\title{
Memória, Cidade e Educação das Sensibilidades*
}

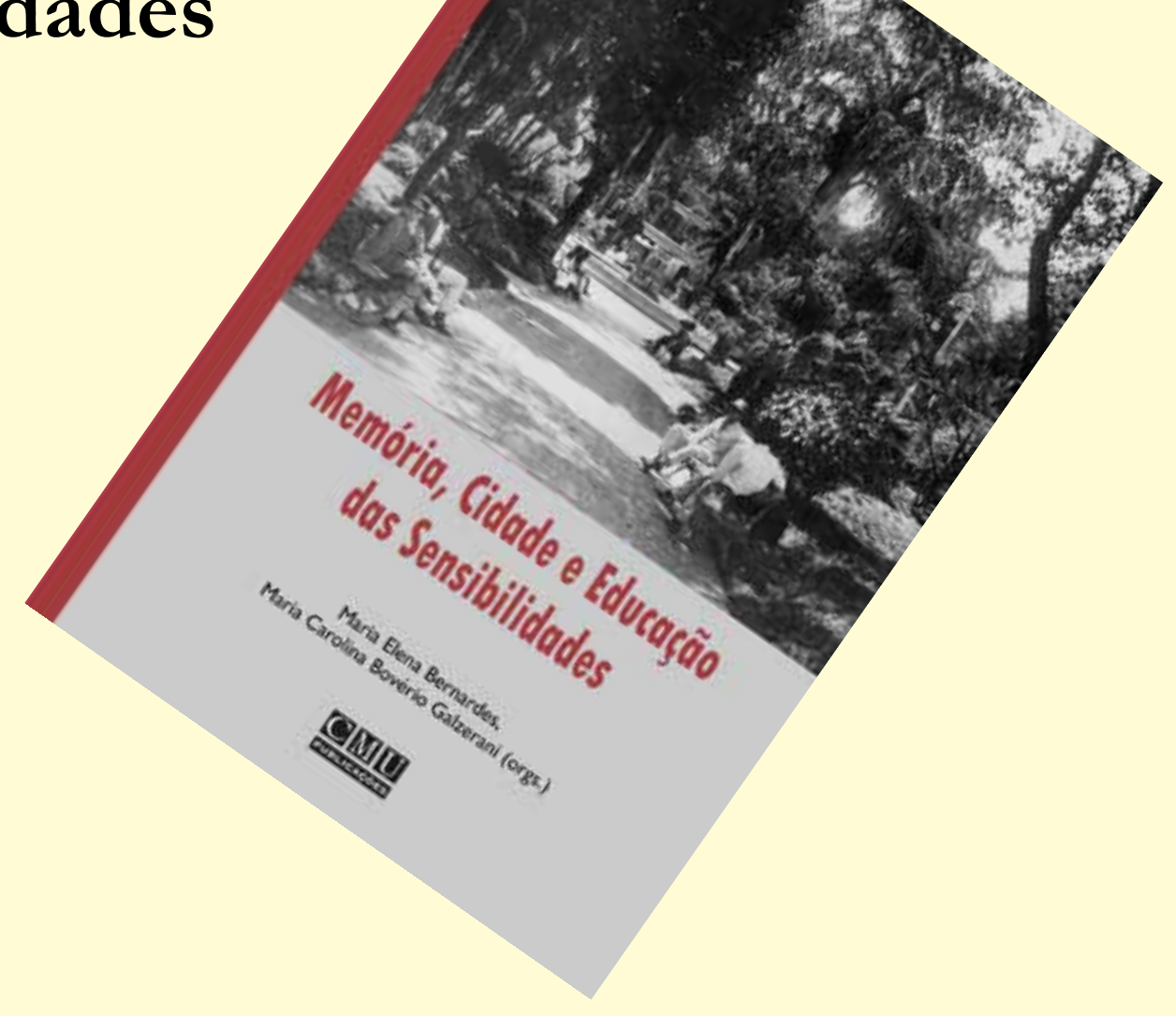

Cláudia Prado Fortuna ${ }^{1}$

O livro Memória, Cidade e Educação das Sensibilidades, organizado pelas pesquisadoras Maria Elena Bernardes e Maria Carolina Bovério Galzerani, é de atualidade premente em suas interlocuções e nos sentidos que movimenta. Os diferentes temas da coletânea surgem como fundantes de novas historicidades e respondem aos desejos e trajetos capazes de revelar um complexo processo da problematização das fontes, pautado por percepções e intuições que permitem ampliar a dimensão do ser sujeito e seus vínculos com a ação.

As abordagens que permeiam as reflexões tecidas na composição dos textos são instigantes e singulares ao revelar escolhas teóricas e metodológicas que embasam as discussões contemporâneas sobre as relações entre memória, cidade e educação das sensibilidades. Nos diferentes textos, os conceitos de representação, de memória e de sensibilidade são as chaves para problematizar as fontes relativas às experiências vividas nas cidades modernas. Os mais diversos documentos deixam de ser apenas suporte informativo, ganham o valor de testemunho e passam a ser vestígios e indícios de acontecimentos socioculturais plurais. Os textos vão, cada um à sua maneira, revelando as diversas faces de homens e mulheres como seres historicamente localizados, com dimensões pessoais e sociais inteiras e dinâmicas.

Para garantir maior unidade discursiva na leitura dos diferentes textos, o livro se apresenta dividido em quatro partes. Compondo a primeira

\footnotetext{
* Trata-se de uma coletânea de textos apresentados no VII Seminário Nacional do Centro de Memória - Memória, Cidades e Educação das Sensibilidades - ocorrido na Unicamp em 2012.

1 Prof. ${ }^{a}$. Dr. ${ }^{a}$ do Departamento de História da Universidade Estadual de Londrina (UEL).
} 
Resenha

parte - Cidade e Memória: um universo a ser (re)visitado - o texto de Maria Stella Brescianni, intitulado Memória, cidade e educação da sensibilidade, nos convida a viver a experiência de nos perdermos pelo bairro de Santa Ifigênia, na região central de São Paulo, por um trajeto marcado pelas camadas de memória da autora e pelo seu estranhamento no encontro com paisagens que já não se encaixavam nas suas lembranças. Neste percurso, ganham destaque as questões sobre memória, arquitetura e sensibilidade visual e problematizam-se as sensibilidades que poderiam prevalecer nos processos de revitalização de áreas estigmatizadas das cidades. A seguir, no texto Imagens visuais, memórias e sensibilidades, Maria Silvia Hadler nos leva a circular pelos bondes da cidade de Campinas nas últimas décadas do século XIX e acompanhar os processos de educação das sensibilidades mediados pelas novas percepções do espaço urbano que, de acordo com a autora, confirmavam cotidianamente valores estéticos e socioculturais comprometidos com uma visão de progresso liberal, positivista e romântica. Fátima Faleiro Lopes também nos traz, em seu texto, Viver, sentir e narrar a cidade: experiências de modernidade, notícias sobre Campinas, agora nas década de 1960, ao propor um diálogo e uma análise sensível e cuidadosa com a narrativa de um guarda municipal que discorre sobre suas memórias de migrante paranaense ao chegar à nova cidade. Neste processo, a pesquisadora vai nos apresentando Campinas pelas percepções, indagações e sentimentos desse narrador.

Compondo a segunda parte do livro, intitulada Memória e produção de conhecimento: ambiguidades e possibilidades, somos contemplados com o texto História e memória: inimigas, mas nem tanto, de Francisco Régis Lopes Ramos, que redimensiona, em diferentes situações, os processos de se dar sentido ao passado. Primeiro, problematizando, a partir do nosso presente, o opúsculo Os monumentos do estado do Ceará, publicado por Eusébio de Souza em 1932. Segundo, analisando as diversas esferas discursivas que fazem referência à figura histórica do General Tibúrcio, uma das estátuas inventariadas na obra de Eusébio e, terceiro, discutindo os problemas decorrentes dos movimentos identitários atuais de defesa da memória e das questões que tensionam e envolvem os campos da memória e da história. A seguir, o texto Desafios da memória para a producão do conhecimento histórico: uma proposta de debate, de Maria Carolina Galzerani, nos apresenta um diálogo expressivo e analítico com a produção de Francisco Regis Lopes Ramos, principalmente no tocante às relações entre memória e história. A longo do trabalho, a autora nos contempla com novas considerações teóricas sobre o tema e demonstra sua concordância com a produção historiográfica do autor capaz de problematizar de forma racional e sensível estes dois campos de conhecimento, memória e história.

No próximo texto, A representação da memória no documentário biográfico, Denise Tavares da Silva realiza uma significativa discussão sobre os desafios e potencialidades encontrados pelos cineastas na realização de documentários biográficos, principalmente no que diz respeito aos lugares da memória e do "pólo imaginativo do biógrafo" nestas produções. Na realização de análises instigantes dos seguintes documentários biográficos - Cartola- música para os olhos (2006), Pierre Fatumbi Verger-mensageiro entre dois mundos (1998) e Um tigre de papel (2007), a autora aproxima diferentes campos do saber e possibilita diálogos sensíveis entre memória, história e cinema. Na sequência, Maria Elena Bernardes e Henrique Polidoro apresentam o texto $A$ mulher no Itamaraty: a conquista de Maria José e as diatribes de uma época. Com narrativa viva e imersa no diálogo com as evidências de uma variedade documental, somos convidados a acompanhar a trajetória da primeira mulher autorizada a participar de um concurso público no Brasil, no ano de 1928. Ao narrar a história de Maria José, primeira diplomata brasileira, os autores contextualizam questões ligadas ao feminismo em uma abordagem não linear e reveladora das ambiguidades e singularidades da vida de uma mulher que acabou por merecer o papel de pioneira na luta pela causa feminista. No texto seguinte, Paisagem, história e memória no Brasil oitocentista, a autora Valéria Alves Esteves Lima apresenta uma elaborada reflexão sobre o lugar da natureza nas iconografias do século XIX e de que maneira elas contribuíram para a constituição de uma dada sensibilidade a respeito do território brasileiro. Compondo a discussão, a autora discorre sobre o papel da Academia Imperial de Belas Artes e do Instituto Histórico e Geográfico Brasileiro na construção de 
uma memória visual da nação, analisa o papel da iconografia produzida por artistas-viajantes e retoma a historicidade dos conceitos de natureza e paisagem.

Constituindo a terceira parte do livro, sob o tema Memória e linguagens: uma questão sensivel, temos o texto Sobre pintura e poesia: a disputa pela memória e a emergência de questões sobre a sensibilidade moderna, de Marcus Francisco Corrêa Carvalho. O autor recorre aos gregos ao retomar o processo de distanciamento que ocorreu na modernidade entre os fazeres do poeta e os do pintor. $\mathrm{O}$ autor destaca que o século XVIII foi crucial na instauração do racionalismo moderno e na disputa pela memória dos antigos. Neste processo, segundo Marcus, foram se instaurando embates teóricos promotores de mudanças e permanências capazes de impactar uma nova sensibilidade nos domínios das artes (promovendo a delimitação de fronteiras entre pintura e poesia), como também na percepção das relações entre homens, natureza e sociedade. Compondo esta terceira parte do livro, Ana Luisa Smolka, Augusta Tie Yamamoto, Daniela Anjos e Nilce Deciete apresentam uma importante discussão sobre os muitos sentidos da memória nos campos da educação e da psicologia do desenvolvimento humano com o texto Ler e ensinar: memória dos gestos em (trans) formação. As autoras apresentam, de forma analítica, reflexões possibilitadas pela pesquisa sobre as práticas de alfabetização, leitura e escrita que tomaram a escola e o discurso como objetos de investigação durante quatro anos de trabalho. Considerando a aula como acontecimento, as pesquisadoras buscaram pelos gestos e práticas de leitura, de ensino, de ensino da leitura e da escrita, localizando-os como lugares de memória, socialmente produzidos, historicamente instituídos e singularmente vividos por alunos e professores. O texto seguinte, Memórias, sensibilidades e porvires: dos trânsitos entre tempos e experiências em práticas de ler, escrever e ver, Maria Angela Borges Salvadori retoma e insere-se na materialidade discursiva dos textos de Ana Luisa Smolka e Marcos Vinicius Correa Carvalho, ajudando a estabelecer pontes entre os dois trabalhos e ampliando as discussões sobre memória, práticas sociais e sensibilidades.
$\mathrm{Na}$ quarta e última parte do livro, Cidade, memória e cultura popular, temos o texto $O$ tradicional na metrópole: proposta para cultura popular na cidade de São Paulo, de Maria Celeste Mira, que tem como principal preocupação caracterizar e problematizar os diferentes processos de apropriação do que se convencionou nomear cultura popular no Brasil. A autora se debruça sobre a contemporaneidade, indicando como a discussão sobre diversidade cultural tem favorecido a retomada de práticas culturais populares e, voltando seu olhar para São Paulo, discorre sobre o que considera as quatro posturas identificáveis quanto ao tema: a folclorista, a voltada para a questão da estética e da resistência cultural, a lúdica e, por fim, a postura engajada. Já com o texto História, cultura e patrimônios regionais: uma experiência de ensino e pesquisa, Elison Antonio Pain faz emergir sua prática como docente do componente curricular História, cultura e patrimônios regionais, compartilhando com os leitores o percurso teórico e metodológico construído com os alunos do curso de matemática e mediado pelos conceitos de patrimônio imaterial, memória e rememoração e narrativa.

Convidamos todos à leitura integral dos textos presentes nesta coletânea. Consideramos que, ao enfatizar o papel das sensibilidades, dos sujeitos e das singularidades, novas maneiras de olhar, sentir e viver poderão ser trazidas à tona e se tornarem legíveis no presente. A focalização cuidadosa da discussão sobre memória é tecida por cada um dos autores em um movimento de pluralidade analítica e reflexiva capaz de revelar a cidade como lócus de representações e de práticas socioculturais plurais nas quais a educação das sensibilidades se mostra como historicamente construída. Em uma época em que a ordem é apagar rastros e onde existe o perigo do desaparecimento de narrativas e da memória, acreditamos que, ao nos voltarmos para novas possibilidades metodológicas de construção do conhecimento, poderemos fazer emergir os sentidos esquecidos de outras histórias. Os textos abrem, assim, um imenso campo de possibilidades que pode nos ajudar a questionar antigas abordagens, trabalhar novas perspectivas e investigar outros pressupostos. 


\section{Referência da obra resenhada}

BERNARDES, Maria Elena; GALZERANI, Maria Carolina Bovério (Orgs.). Memória, Cidade e Educação das Sensibilidades. Campinas, SP: Unicamp/CMU, 2014. 